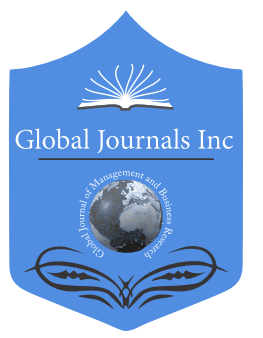

GLOBAL JOURNAL OF MANAGEMENT AND BUSINESS RESEARCH: A ADMINISTRATION AND MANAGEMENT

Volume 20 Issue 2 Version 1.0 Year 2020

Type: Double Blind Peer Reviewed International Research Journal

\title{
Human Resources Challenges in Apparel Industry in Sri Lanka
}

\author{
By Dr. Indumathi Welmilla
}

Abstract- This study aims to identify the human resources challenges existing in the apparel sector of Sri Lanka and provide recommendations to secure with managing the barriers to go ahead with future sustainability in the industry. The research approach is qualitative and followed the case study method. Face to face interviews was the method of collecting data by following a semi-structured questionnaire for the research, and the data analysis method was the thematic analysis. The finding demonstrates nine core human resources challenges in the apparel industry in Sri Lanka.

Keywords: apparel industry, high competition, human resources challenges scarcity of labor, less attractiveness, poor work ethics.

GJMBR-A Classification: JEL Code: 015

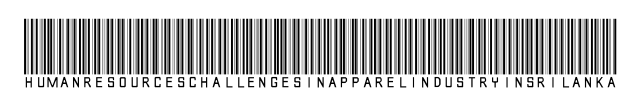

Strictly as per the compliance and regulations of:

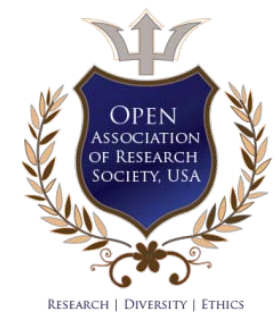

(C) 2020. Dr. Indumathi Welmilla. This is a research/review paper, distributed under the terms of the Creative Commons Attribution-Noncommercial 3.0 Unported License http://creativecommons.org/licenses/by-nc/3.0/), permitting all non-commercial use, distribution, and reproduction in any medium, provided the original work is properly cited. 


\title{
Human Resources Challenges in Apparel Industry in Sri Lanka
}

\author{
Dr. Indumathi Welmilla
}

Abstract- This study aims to identify the human resources challenges existing in the apparel sector of Sri Lanka and provide recommendations to secure with managing the barriers to go ahead with future sustainability in the industry. The research approach is qualitative and followed the case study method. Face to face interviews was the method of collecting data by following a semi-structured questionnaire for the research, and the data analysis method was the thematic analysis. The finding demonstrates nine core human resources challenges in the apparel industry in Sri Lanka.

Keywords: apparel industry, high competition, human resources challenges scarcity of labor, less attractiveness, poor work ethics.

\section{InTRODUCTION}

S ri Lanka's apparel industry widely began to grow in the country after the open economic policy of 1977 (Industry Capability Report, March 2017). With the implementation of a free financial plan, more foreign investment came into Sri Lanka due to trade-friendly environment factors. Sri Lanka became a more attractive country for the apparel industry due to the open economic policy, and Multi-Fiber Arrangements (MFA) (Dheerasinghe, 2009). The MFA is a system of quotas designed to protect garment industries in first world countries by slowing down the speed of globalization (Institute of Policy Studies, 2005). The apparel industry became one of the leading contributors to the export revenue of the country and is well known and expert in this industry due to the highquality garments at competitive prices and holding ethical practices backed by legislations.

Sri Lanka is contributing to the apparel industry, mainly in the Asian region, and now India, China, Vietnam, Bangladesh, and Cambodia became more competitive countries to Sri Lanka. After the MFA, many developing countries in the Asian region, such as Pakistan, Bangladesh, China, India, and Sri Lanka, engaged in the apparel industry massively (Dheerasinghe, 2009).

India becomes a leading country in the global apparel industry, and they expect to accomplish $\$ 80$ billion from textile and apparel exports in 2020 (Anand \& Kheterpal, 2014). Government of India is working on their $11^{\text {th }}$ five-year plan and its included substantial investment in apparel and textile trade and investments

Author: Senior Lecturer, Department of Human Resource Management Faculty of Commerce and Management Studies, University of Kelaniya, Sri Lanka.e-mail: iwelmilla@kln.ac.lk in new textile parks, various incentives, and training programs. (Anand \& Kheterpal, 2014).

The budget proposal published for the year 2015 stated that the Sri Lankan government is intending to reach to top ten high-quality garment manufacturers in 2020 with the earning of US $\$ 10$ billion. Sri Lanka focuses on its future challenges in the apparel industry and how to overcome them to reach up to the country's expectations. The main strengths in the Sri Lankan apparel industry are highly literate workforce, strategic location, favorable infrastructure, product quality, and development in speed solutions. (Derasingha, 2017)

However, the Sri Lankan government is looking to become the top ten high-quality garment manufacturers in the year 2020, its dream outlining the plan for 2020 mission says that the expectation is to achieve GDP of US $\$ 150$ billion by maintaining the unemployment rate less than 3\%(Budget Proposals, 2015).

The new trends in the global garment industry with the aim of more productivity concepts and cost minimizations become another challenging factor in the apparel industry in Sri Lanka (Ranaweera, 2014). Labor turnover and increased rates of absenteeism are now become a $\mathrm{g}$ crisis in the apparel industry and were evidence that those have limited the industry to reach their expectations (Abdur \& Atm, 2015).

The human resources area as the human resources factor is critically more important to the organization. More effective and profitable organizations build-up by talented, qualified, and trainee employees, thus the employee issues in an organization are well known as the lifeblood of an organization (Thammita, Seedevi, Jayarathna, Welianga, Madushanka, 2010). Therefore, when an industry is facing challenges, it is more important to pay attention more to the human resources asset.

It is worth to note that Sri Lanka has recorded a high unemployment rate of 12\% in 1992 and 4\% in 2016 that shows slightly decrease, but it still archives the highest trend to the departures for foreign employment opportunities, and during the period starting from 2001 to 2015 there has been upward trend for moving to the overseas employment opportunities by the skill workers, unskilled workers, and other categories. (Samarasinghe, Ariyadurai, \& Perera, 2015).

There is a severe challenge to the apparel industry in Sri Lanka. Therefore, it is necessary to 
examine the future and its challenges critically to find out the solution in the long term stability of the apparel industry in Sri Lanka. Moreover, the Sri Lankan apparel industry is actively connecting with the working population; therefore, this study aims to explore the Human resources challenges associated with the apparel industry in Sri Lanka.

\section{il. Literature Review}

The export-oriented production of the readymade garment industry in Sri Lanka has begun in the 1970s and expanded rapidly after the introduction of trade liberalization of the economy in 1977. In the early era, direct foreign investment marked as a more important factor in industry establishment and growth, but lately, domestic capital became similarly necessary. The MFA set up a quota system, and it granted an assured market for countries such as Sri Lanka, India, China, Hong Kong, Taiwan, and Korea in the European Union, the USA, and Canada (Kelegama \& Epaarachchi, 2003). According to Thilakaratne (2006), during the late 1990s, the apparel industry grew at $18.5 \%$ per annum, and the export-led expansion of the industry led to the replacement of tea by garments as the nation's largest foreign exchange earner. The development of the Sri Lankan clothing industry has been remarkable in terms of its contribution to GDP, exports, foreign exchange earnings, and employment generation. Thilakaratne (2006) further discussed that a considerable proportion of the apparel factories in Sri Lanka are small and medium scale. However, the small and medium scale industries export merely about $15 \%$ of the total exports, and the industry is dominance by a few large firms, which claim to about $85 \%$ of the total value of exports (Dheerasinghe, 2017).

The highly trainable, skilled, and literate workforce is one of the most important factors that has contributed to the high development of the Sri Lankan apparel industry. (Samarasinghe, Ariadurai, \& Perera, 2015).In the global economy, the Sri Lankan apparel industry has faced a significant challenge in strengthening competitiveness. (Ranaweera, 2014). As described by Gavranovic(2018), most of the industries now a day are facing such difficulties as profoundly changing technology, globalization, unpredictability, and turbulence. So it is worth to perceive the situation concerning the Sri Lankan apparel industry as it is the highest sector contributing to the Sri Lankan economy.

As a significant organizational element, human involvement is desirable to discuss due to several human resources problems such as high turnover, absenteeism, and these problems now have become vast barriers to achieve the organizational objectives in the apparel industry. (Kotawatta, 2013). The average employee turnover in an apparel factory is nearly about 60 percent per annum and 20 percent skilled persons leaving the industry for migration opportunities in Sri Lanka. (Liyanage \& Galhena, 2014).

Kelegama and Epaarachchi (2003) stated the reasons for high turnover and absenteeism of apparel workers are due to the poor working environment, worker stress, and poor social local perception of the apparel workers. These factors caused the low productivity of the sector and highly contributed to inadequate human resources practices in the industry. As per the view of Kotawatta (2013), responsible parties manage workers who begin in the apparel industry have to have a hard power to control the labor towards organizational success in the short term and long term.

The innovations and technologies oriented methods have made new information, capacity, and ability necessities of the human asset in the apparel industry (Lohar \& Gopal, 2013). Information, capacity, and ability necessities for the employee asset, Computers, internet, automated machinery have become major innovative products in the apparel workplace (Lohar \& Gopal, 2013). The industry has welcomed these new techniques, but the Indian apparel industry has indicated that the same has created challenges in the industry. The main problems they have identified due to technological changes are ongoing developments in the human capital and talent requirements of the jobs (Lohar \& Gopal, 2013). Futhrmore, Anand \& Keterpal (2014) have stated that by giving more training opportunities internally to develop the use of machinery and equipment at the workplace is increasing productivity. Low educated or lack of technical education of employers are harmful to the Indian apparel industry (Lohar \& Gopal, 2013). The sexual harassment wasprevalent in the garment factories, and there were high gender base discriminations in this industry (McMullen \&Majumder, 2016).

High Employee turnover is a common problem for the apparel industry, and there are key factors affecting employee turnovers such as the frustration of the employee, limited career development opportunities, for own betterment and peer's behaviors (Farooqui \&Ahmed, 2013). Even though there is sufficient literature available on employee turnover, there are no precise models to find out why employees leave their working places (Lee \& Mitchell, 2001).

Bangladesh's economy has been highly considering the ready-made industry, and employee turnover, deeply related to the organization's productivity, and this has become a major human resources problem in Bangladesh ready-made garment factories(Sikdar, Sarkar \& Sadeka, 2014). The insufficient income of the employees becomes the prime reason to quit from employment, and they had gone for higherpaying jobs and also, that people who are not happy with the job duties, risk and challenges caused 
employees to quit from the employment (Shamsuzzoha \& Shumon, 2010).

Women harassment, employee discrimination, child labor has become growing problems in the Bangladesh garment industry. (Ullah, Sunny \& Rahman, 2013). In the Cambodian, lower training levels and educational levels have become a constraint to the labor productivity of the garment industry (Natsuda, Gota \& Thoburn 2010). Furthermore, in this country, the poor working condition has lead employees for unrest situation (Gabriel, 2015).

\section{Methods}

Given the objective of this study, the researcher conducted thirty-five qualitative interviews with the human resource managers in the apparel factories in Sri Lanka. The population of this study was the human resources managers in the apparel factories of Sri Lanka. For the study, the researcher has selected thirtyfive apparel factories as the sample by using a convenience sampling method.

As the research was trying to address a fact that is related to human resources, which is very much subjective, and high weight on the qualitative nature of data. Thus the researcher used both primary and secondary data. The basis of this research approach is to collect primary data by interviewing the human resource managers of the purposively selected apparel exporting companies in Sri Lanka. However, the researcher also realized the importance of collecting secondary data while analyzing the primary data because all the secondary data has complemented the primary data and so possibly increased the acceptance of the primary data.

In the questionnaire, there are some structured and semi-structured questions used to collect primary data through the interviews. The initial questions provide general perceptions about the Sri Lankan apparel industry, and it is followed by some queries that aim to provide facts that affect to the apparel industry. The next few sets of questions aim to provide a deeper understanding and an inside picture of the apparel industry and also the human resources challenges faced by the enterprises. The interviews end with comments from the interviewees on the studied object. The main questions were supported by probing questions to ensure that all required details captured. The main interview questions and the probing questions were developed based on the theories available. Table 1 shows sample questions that use to explore the study's aims.

Interviews were provided the necessary depth information for this study. Although it was a hard job to interview some of the interviewees, it was essential to serve the purpose of the study. At first, Interviewees were requested by a phone call to reserve their valuable time to give an interview date and time. Before starting the interviewing process, the first researcher introduces herself and explains the interviewee the purpose of the study and aim. After confirming the formal consent of the participants and satisfying the ethical requirements of confidentiality, the researcher recorded interviews and taped the transcribed interviews into a format suitable for N- Vivo processing (Silverman, 2013). In this case study method researcher has been chosen the thematic analysis as it is a widely used qualitative data analysis method. Mainly thematic analysis method identifies the patterns of meaning across the dataset that provides findings to the study's aims.

The researcher followed the basic guidelines given by the thematic analysis (Braun \& Clarke, 2008) first read the content of the interview recorded during the face to face in-depth interviews. The process of converting recorded data/notes into a word-processed document took 1 hour and 45 minutes to transcribe. In the next step, each sentence of the interview transcription was coded in a systematically according to the main numbering of the semi-structured interview questions. Highlight the key points and quotes to the illustrated points by giving concepts with labels given to line by line. The ideas similar in sound were merged and developed the concepts at the end of the open coding process of each interview transcription.

Table 1: Sample questions from the interview protocol

\section{Sample Questions}

1. What kind of challenges faced by human resources management in the Sri Lankan apparel industry?

2. Could you please share with me what human resource challenges associated with your organization?

3. Being one of the famous apparel factories in Sri Lanka, do you have any human resource challenges and how you find difficulties with those challenges?

4. What are the steps you have taken so far to overcome the HR challenges?

5. Could you please share with me any other remedial actions you would like to see to overcome these challenges?

6. Do you have any understanding of the other Asian countries about the situation?

7. Could you please list down the identified challenges?

8. How have you been identified these challenges? 


\section{FINDINGS}

In this section, the researcher report findings and broad concepts by following study aims. All human resources managers/operational managers responded to the survey were faced with identified challenges when working in the apparel industry in Sri Lanka. Finally, the researcher was classified the human resource challenges under nine categories such as; Scarcity of labor in the industry, High Competition from the rival enterprises and parties, Poor work ethic including absenteeism and turnover, Lack of technological development, Longstanding legislations and extreme social compliance requirements, Different management skills on the people management, Negative social image /less attractiveness to the industry, Different attitudes and decision making by the people and Lack of health and safety needs and awareness on sexual well being.

\section{a) Scarcity of labor}

Excess demand for work becomes a severe concern and challenging factory for the apparel sector. All respondents have pointed out that they struggle with the shortage of employment, especially in the operational level job categories. In the previously conducted studies also indicated that there was a sharp drop in the apparel employments after 2003 (Kelegama, 2009). Labour is the necessary input to the apparel sector, and with the lower retention rate of the operational level workers, demand for labor has been increased day by day and a higher labor shortage of 40\%recorded in Sri Lanka (Central Bank Report, 2017). All the respondent reported that they faced difficulties about the labor shortages, and there are no people for them to recruit event, as shown in the following quotes:

The first critical challenge is enrolling people. When it's come to the apparel sector, machine operators are crucial. As per my knowledge, the main issue is recruiting people. It is now challenging to employ skill laborers for factory operational jobs.

There are many vacancies currently in the enterprises Sri Lankan apparel industry due to a lack of suitable replacements. It's tough to fill this gap between the required human resources and the current resources that we have.

Dheerasinghe (2009) has identified that the lack of labor becomes a challenging issue in the Sri Lankan apparel industry. Further revealed has been made, and it discussed that many Sri Lankan operations moved out of the country to the other Asian countries due to the scarcity of labor. In the present context, the majority believed that there is a high demand for work, but the supply of the workforce is a critical challenge due to the scarcity of labor.

\section{b) Negative social image/less attractiveness}

Few respondents explained to the study that there is poor social recognition for the people who are working in the apparel industry, and that perception reduces people's interest in looking at the apparel sector job opportunities. This lousy reputation was given to the newcomers by the media, and different studies conducted from time to time and previous incidents happened in the garment industry around. There is poor social recognition for people in the apparel industry. Thus, this is one of the most disadvantaged to keep experienced core employees in apparel companies. Therefore, employees are looking for jobs in other sectors after sometime. Due to these things, the apparel industry faced significant challenges in human resource management practice. The following quote supports this view:

Yes, there are labor shortages, poor social recognition on apparel jobs.

In Kelegama's (2009) study, he has identified that poor social recognition given to the apparel industry-oriented job opportunities in Sri Lanka. Another study has noted in his work that the reason for not attracting the labor into the apparel industry in Sri Lanka because of poor social recognition it gained (Hancock, Carasta this, Georgiou, \& Oliveira, 2015). Garments workers did not get social status and were neglected from society as a lowly recognized profession is the other challenge in the apparel industry in Sri Lanka. The literature mentioned above also supported the researcher's finding in this study, and the negative social perception of the Sri Lankan apparel industry has become a challenging problem in human resources.

\section{c) Different attitudes and decision making of people}

Employee working attitude is also an essential factor to consider to take the human resource management decision of a company. Employee working attitude changes organizational culture, develop employee commitment, trustworthiness, efficiency, and effectiveness of job tasks, etc. Poor employee attitude creates unresolvable problems in the human resource process of apparel companies in Sri Lanka. Different types, ages, social groups of employees are working in apparel companies since they have poor attitudes that have to tolerate and corrected when managing people in the apparel industry. Therefore, the failure of employee attitudes is the primary human resource challenge. The following representative comment illustrates this challenge:

In garment factories can be seen as different attitudes of the employees. It is complicated to convince them to work. Some are arrogant and hard-core people. There are some areas in and around factories and those areas reckoned as very horrible and arrogant 
villages. People are coming from those areas also not willing to adhere to the other instructors, superiors, and not respecting other supportive members and always make demands for their satisfaction only.

Some employees are lazy from their nature, and they expect a comfortable work-life and get monetary benefits. There are many unemployed youths in the rural distance areas in Sri Lanka, but it is still challenging to bring them to the garment industry due to their poor attitudes. However, youth people wish to dress nicely and engage in work with fewer responsibilities, as described in the following:

The biggest issue now in the industry is an employee is looking for a comfortable, relaxing job opportunity. Even though we provide different types of financial and none financial benefits to attract them still, it is challenging to retain the labor leakages and attract newcomers.

The majority of females are working for the apparel industry in Sri Lanka. Available literature also proved that almost $70 \%$ of the Sri Lankan workforce contains inactive women and central causes behind this fact were women leave their jobs after marriage, maternity leaves and look after the education needs of their children. Following is explanatory and showed how female participation had been declined based on their or their relatives' decisions.

Five years before, it was 90\% female and 10\%, male. But now we started hiring many males for femaleoriented jobs; therefore, current representation is female $65 \%$ and male 35\%.

Yu Ru Hsu (2011) stated that there is a negative relationship between work-family conflicts and job satisfaction. Personal issues connected with the family and members deemed employees to think that their working environment is not favorable, and rigid rules are there to control them. Employees had several personal issues at home when they were staying outside from home for employment, so they find it challenging to manage it correctly. Some employees are coming to work from their homes, and they also struggle when they have personal problems to be solved. Employees tried to off from the job duties and resolved their matters, but there is pressure coming to them back again on their absences from the authorities in the enterprises as there are different leadership styles, and those vary from enterprise to enterprise. Therefore, employees finally decide to work in free working arrangements where they have not stayed with rigid rules and regulations. Temporary employment helps employees to stay out of strict rules and regulations and work only when they want. Therefore, employees were attracted to temporary operating companies in the apparel industry. For example:

The recent issue in the contract labor/casual workers. We are struggling to hire people, but the people are doing casual nature jobs; there are ample of people with them.

The finding of the study proved that how different attitudes of the people change their mind-set in the apparel industry jobs. The literature explained that the factors influenced views rose from socially, own experience, and learning. (Cherry, 2017). In this study, respondents have described what the expectation of the new job seekers are, how the attitudes changed the behaviors of some employees from socially, the job was picked by the job seekers with their short term decision makings, and so on.

d) Lack of strong work ethic with high absenteeism and turnover

High employee turnover and absenteeism in the operational workforce was another identified human resource challenge by the respondent in the Sri Lankan apparel industry and highly discussed. Employee turnover is a foremost problem for apparel companies because that directly connected to the high human resource management cost on recruitments, training, etc. Available literature proved that the average turnover of an enterprise was 60\% per annum, which is high (Samarasinghe, Ariadurai,Perera, 2015).

Absenteeism is the other significant challenge in all enterprises as per the respondents. The majority of female employees are working in the apparel industry. Female employees usually show big absenteeism problems due to family matters, maternity leave, etc. All these causes to increase employee absenteeism rates and employee turnover rates and it is a human resource challenge, as a quote of a respondent:

There is vast absenteeism of the operational workforce, and it cannot be controlled or find out any solution yet. Employees are giving various types of reasons and some long absences finally ending with the turnover of the employee. One of the critical reasons we find out is the majority are the borders; therefore, their loveable in the families such as kids, husband, parents, relatives are living in the villages. Some family members are sick due to aging and nobody to take care of them.

It was found that there was poor work ethics in practice in the garment industry of the employees and became a human resources challenge too. These people have less focus on career development. Mostly lower-level employees are working only to earn. They were not much interested in developing a proper career. Therefore, their absenteeism rate is high and less commitment to the workplace and it is another human resource challenges faced by apparel export companies in Sri Lanka.

Labour turnover and absenteeism become a pervasive crisis in the apparel context, and these challenges limit the organization's development and expectations. In the Sri Lankan apparel industry, 
turnover, and the absenteeism of the employees become more barriers (Kotawatta, 2013). This literature proved the researcher's finding in the study, and finally, the poor storing work ethic, including the absenteeism and turnover, become the challenges to the apparel enterprises in Sri Lanka.

\section{e) Technological development}

Few respondents have identified that Human Resources challenges as highly dependent on labor involvement jobs rather than on automated machinery and high demand for labor exist as a result. Still, enterprises demand laborers and struggling without meeting expected labor demand. The interviewees reported that during the last four decades in the Sri Lankan apparel industry, there had not seen any noteworthy technological development in the apparel sector, and demand is still there for manually operated machinery:

The reason behind the high demand for sewing machinist is the manually operated machinery, which I have highlighted in your previous question.

Innovation is a nessential success in the business environment. These people are less responsive to the innovative requirements of the apparel company. Therefore, supervisors were hard to adapt the employees to new systems and technologies implemented. However, these core employees are not much positively responding to innovations because they are not having much knowledge about the importance of innovation. Thus the novelty is one of the main limitations faced by the human resource department of apparel companies in Sri Lanka.

Ranaweera (2014) showed that innovation is the key to the Sri Lankan apparel industry in long-term sustainability. Enterprises face challenges due to rapid changes in technology (Agbor, 2008). The apparel industry becomes a very competitive sector in the world economy and Sri Lankan economy; therefore, to reach the 2020 mission, it is required to in line with the global technological trends. Machinery upgrading to be in line with the universal latest technology gained a competitive advantage and made a lot of monetary savings, which will help to demand at a competitive price. To obtain a productivity workforce and become price competitiveness, the Sri Lankan apparel industry must invest in the technology, and it identified as a need in the Sri Lankan apparel industry. As explained in the study, results necessary technological advancement will ease the work-life, stress, and pressure of the garments workers and provide an excellent solution to the scarcity of the labor.

f) High Competition from the rival companies and others

The respondents have given their concern about the difficulty of attracting newcomers to the enterprises, and several reasons were lying under the hardship to attract new employees in the company. Those were competitive salary paid by the enterprises, different types of facilities such as shift hours, welfare benefits.

In the first ear of the newcomers engaged in the industry zone, it is hard for them to adopt the environment as well as to the boarding environment. In this situation, what organizational offers and employee requests were not in line and created dissatisfaction with the new comer's mind. It is hard to pay a high salary to employees work in the apparel industry since the management of the apparel industry had to face problems with employee turnover because of salary. There is a high tendency for employees to worked in casual work or daily paid wage nature jobs. All these jobs are temporary and available only vacancy is existing in the enterprises. Informal human resources laborer suppliers are prevalent in the garment industry, and more employees are joining with these sectors even they were not paid superannuation benefits or statutory payments. They expect the daily sum of money to be earned and manage today's living expenses. Respondents explained that attitudes of the employees and early stages in the apparel industry employees worked and aimed to receive something big to arrange their future family activities after completion of the consecutive five years and earned the gratuity:

The biggest issue now in this industry is an employee is looking for easy, relax job opportunities. Even though we provide different types of financial and none financial benefits to attract them still, it is challenging to retain the labor leakages and attract newcomers.

The current trend is now employees going for casual nature jobs. There are vast numbers of employees practicing this method, and we can see there are many informal suppliers too. These workforce agencies are not complying with the existing labor legislation, but still, the workers are preferred to resign from their permanent jobs and join with the workforce jobs.

The apparel industry is highly competitive and stressful. A large workload develops unfavorable working arrangements for employees. Therefore, most employees were unable to meet the target in the job, which was also caused by employee high labor turnover in the apparel industry and joined with the temporary work provided by the casual labor suppliers.

Kelegama (2011) revealed that competition had been built up by the temporary labor suppliers and other rival enterprises established in the Sri Lanka export processing zone. This factor further increased the demand for labor, and enterprises should have to play a competitive play to survive in the industry. 
g) Different management skills in people management

The leader is the main person in a company. They are responsible for managing the human resource of the company as well. Poor leadership leads to a lack of success in a company. Leaders' attitudes and behavior must be different based on the organizational culture, industry, and other factors. All leadership styles would not be applied to manage the human resources of apparel companies in Sri Lanka. Respondents have seen significant leadership style mismatch with facts of the apparel industry. Therefore, some apparel companies were not successful. Weak leadership attitude influence on reducing the job satisfaction of employees of the apparel industry. It should be something in another way, and they should drive the people to the expectation and should be smarter to change the employee attitudes into the "I CAN" concept.

In Dharmasiri's study (2012), he explained well about this people management skill in the current context, and it said that being strategic in managing human resources is very important. This study as well proved that people who manage their human resources at a different level in an apparel enterprise and they strategically focuson managing their people.

\section{h) Longstanding Legislations and extreme social compliance requirements}

Due to the political and legal environment that different labor laws came into action in Sri Lanka regarding human resource management. All companies have to obey to follow the labor laws of Sri Lanka and social compliance standards to survive and make delighted their buyers/customers. Furthermore, companies had to allocate specific expenses such as tariffs and barriers when exporting apparel to other countries. Finally, all these add to the high production cost and reduction of profitability of manufacturing. Some companies faced considerable hardships with lower-level net profit margins. Therefore, it is time to rethink about legal practices and social compliance standards currently in practice from ages eras ago with the changes of the time. Losing out GSP + discussed in the literature showed how Sri Lanka face difficulties and how other Asian countries developed a lot with these reliefs.

The apparel industry is in line with rigid rules and regulations in the working environment from some compliance \& quality expectations. To meet customer quality standards, apparel companies had to follow strict rules and regulations. However, employees are not interested in these rules and regulations. Therefore, refusal of rules and regulations cause quality issues of the production and other employment issues in the apparel sector. As discussed in Samarasingha et al. (2015), the labour legislation in Sri Lanka is very complex. As a result, working hours, types of contracts were restricted by the longstanding legislations. The upgrading of these requirements needs to meet the present conditions.

\section{i) Lack of Health \&safety facilities and awareness on sexual wellbeing}

Aforementioned by the respondent's majority of employees were staying in boarding houses and working for apparel companies in Sri Lanka. That means the majority of employees were staying out of their homes. This situation created poor health and safety issues for employees. The majority are boarded employees as per the respondents, and they find difficulty in lodging with basic needs matching their expectations and budget. Most of the new female employees have faced issues with less knowledge about sexual wellbeing, and early marriages resulted in sexual exploitation, which finally led to stop the employment from their jobs. The following quotes support this view:

Employees also faced difficulties in their boarding due to safety problems, high living costs, and expenses. Therefore, they started to shift to distance area factories. Especially female faced difficulties in their barding and, some females got into a relationship with crummy people and fallen into the problems. These factors resulted in parents in the suburbs to think about not allowing their children to go out from their hometowns to the garment industry areas like Katunayake and get boarded and work.

On the other hand, there is develop an unfavorable working condition around the lack of experience of unskilled laborers. Therefore, it is obvious to have a high labor turnover. Labor turnover is associated with and influenced by senior recruitment cost, selection cost, and training cost. Likewise, internal human resource cost and production cost incur the lack of experience /awareness of newcomer laborers in apparel export companies in Sri Lanka.

Laborers coming from far away distant places were logged in the boarding and were abundant with many problems financially, mentally, and physically as the new locations are hard for them to adopt. As a result, they have to face many social issues that describe in this study. Another researcher identified that health and safety become a challenge for the apparel industry (Thatshayini \& Rajini, 2018). The researcher of this study identified that not meeting the basic expectations of the employees in their health and safety needs, they found difficulties and adapting to the new urban, they were automatically addicted to some severe problems.

Respondents said about high turnover, and absenteeism resulted inmulti-taskers employees who are having additional responsibilities. To fulfill carder shortfall in the operations, the factories put newcomers in the workflow even with a lack of experience, but filling 
up the vacancies is of utmost importance instead of absent employees. Also, the lack of knowledge of new employees in the apparel industry causes to increase errors in the working environment and quality issues of apparel production. As a result of the incompetence of unskilled labor leads to considerable cost and problems in the final production output of apparel companies.

Most employees work in the apparel industry and are young, where these employees have issues due to early marriage and sexual wellbeing. They faced hardships in managing work life and personal life. Therefore, these employees left the job in a short time, create issues in the working environment, increase absenteeism, etc. All these issues explain Human Resources challenges in the workplace and affected the smooth operation of the enterprise.

The apparel industry of Sri Lanka has high employee turnover rates; thus, companies recruit employees every day because they showed a higher number of vacancies in any day. However, recruitment was critical due to salary, working time, rules and regulations, interest to carry out temporary jobs, competition, and other factors. The majority of employees were staying in boarding places since they took some time to adapt to the new environment. These types of personal matters were also caused by the reduction of productivity of employees and increase high employee turnover and absenteeism.

\section{Conclusions}

\section{a) Summary and Implications}

The primary purpose of this study to identify the human resources challenges faced by the apparel industry in Sri Lanka. Current research has been identified scarcity of labor, less attractiveness to the apparel industry jobs, different attitudes, and decisions made by the people, lack of strong work ethic including turnover and absenteeism, lack of technological development, lack of health and safety needs and inadequate knowledge in sexual wellbeing, different management skills on people management, high competition from the rival enterprises and parties and longstanding legislation and extreme social compliance requirements become the barriers to the apparel industry in Sri Lanka. Also, these challenges have negatively affected the operational process of apparel enterprises.

Training and development are helping to trains the employee to perform well in the organization. Training and development increase employees' personal and professional skills and knowledge to carry out their job without errors. According to Lohar \& Gopal (2013), raising the employment strength is mandatory for smoother operation with a competitive advantage. The survey findings have shown that the majority of respondents are low-educated or not getting any technical education. Also, training and development motivate the employee to work in the organization and the ability to manage the workload appropriately. As a result of that employee gets appreciation and recognition from the workplace. Therefore, train and develop employees to avoid existing HR challenges in the workplace.

Salary or financial benefits are the primary purposes of the lower level of employees of the apparel industry. Therefore, employee incentives are the leading employee motivational factor of the apparel industry. Financial incentives attract and retain employees of the organization. Furthermore, employees tend to attend work every day. As a result of economic incentives that apparel companies can reduce employee absenteeism and an employee turnover of apparel companies in Sri Lanka. As described by Mathis \& Jackson (2007), employee turnover means leaving an employee from the existing place to other organizations, and it is a combination of both voluntary and involuntary leavers. Therefore, providing attractive financial incentives to employees of apparel companies in Sri Lanka will increase productivity.

All the apparel companies provide a competitive salary, benefits, and facilities to employees. Employee attracts to the organization which offers higher facilities. To more facilities that employees tend to work committed and high quality. Therefore, another recommendation for the apparel companies in Sri Lanka is to provide sufficient facilities in monetary and none monetary forms to employees.

The working environment is another factor that creates a proper workplace for employees. Employees leave the company due to a poor working environment with stress, high workload, etc. The working environment should be friendly to employees who work to achieve given organizational targets. Therefore, supplement a favorable working environment in the organization lead to reduce the HR challenges.

Apparel companies update with different technologies from time to time to meet the quality of productions.

Further, companies introduce several quality systems and processes to complete the work in apparel companies efficiently. These systems contribute to reduce employee errors, train employees to work in a particular quality, get additional benefits to target achievements, etc. These types of activities help to motivate the employee to work in full commitment.

Mentoring changes employee behavior and attitude in the workplace, positively change employee thinking towards the organization. Employee work-life balance, solving of family matters during the work, and employee personal development are possible to done by using mentoring programs. Employee motivation will reduce the human resource challenges of the apparel companies in Sri Lanka. 
Communication is an active process that can be solved problems in any place. Effective communication communicates about essential massages among employees and employees \& organization. Proper communication helps to deliver organizational objectives with employees and employee expectations with the organization.

Apparel industry workers have a poor image from society due to several reasons such as wrong imagination about the behavior of apparel industry workers, problems faced by apparel employees, etc. All these adverse facts made the false image of the apparel industry. Therefore, effectively conducting employee management in the garment industry of Sri Lanka, when providing necessary counseling services to employees to change their minds to make correct decisions, strengthen employees to face ongoing problems, and build a proper image on garment workers will be addressed the HR challenges.

The flexible working arrangement is essential to encourage the employees to work in an organization. Apparel industry workers are mostly women who are responsible for working in the home, children, parents, and family. They are holding responsibilities at home and in the workplace. Flexible working arrangements create considerable satisfaction and time allocation for employees to manage work-life balance. Therefore, develop flexible working schedules in the apparel companies in Sri Lanka is a recommended solution.

Women have a considerable problem of look after their children during work time. Daycare center facilities are significant to them to manage work and family matters effectively and successfully. Establishment of a child daycare center activities is a method to develop in the industrial zone of Sri Lanka.

To overcome these human resource challenges that companies have to make several decisions such as employee training and development, employee incentives, provide facilities to employees, a supplement of a favorable working environment, and introduce new technology or processes or systems or concepts.

Further, if managers make potent actions such as providing more training, employee mentoring, practical workplace communication, employee management, and build a proper image of garment workers will overcome existing human resource challenges. Training and development activities reduce employee errors in the working environment and motivate the employee to work in the company, which leads to reduce employee turnover. Employee mentoring is also another employee motivational method to make them work a long time in the apparel company. Effective workplace communication ensures employee internal communication, collaboration, and work relationships. Employees would like to work in proper working condition with the appropriate workplace communication and management activities of the management of apparel company.

Apparel companies gained positive initiatives such as to pay a good salary, provide employee benefits, flexible working arrangements for shifts, the establishment of a child daycare center inside the Export Processing Zone, and an induction session organized by the Board of Investments (BOI) in particular time frames in the Export processing zone in Sri Lanka. Excellent salary, employee benefits made employee motivation with monetary. Further, flexible working arrangements and daycare center facilities help to manage their work-life balance. Induction session enables to train and motivate the employee to work in the organization and identify working culture when they are entering to the new job. All these activities are useful to develop a positive attitude of employees to work in the garment industry where management was able to overcome existing human resource challenges. However, still, some issues are remaining human resource challenges in the business context. Therefore, the proper assistance of employee authorities over come other human resource challenges effectively.

Further, employees have suggested ways to overcome human resource challenges in the future. Apparel employees were having issues with their reputation in society since they could like to build an image on the apparel workers. There are several methods to introduce attractive schemes to apparel workers for their development, such as provide loans for favorable interest rates and provide special discounts to buy products from duty-free. Most employees who are working in the apparel industry would attract to salary, benefits, and incentives. Therefore, the promotion of industrial zones salary, bonus, and incentive schemes cause to attract new employees towards apparel companies in Sri Lanka. Most apparel companies are not even following basic labor laws since. Thus monitoring the workforce of suppliers by government bodies in a systematic way can reduce human resource challenges.

\section{Limitations and Future Research}

The findings reported in the present study must be considered in light of the limitations regarding its qualitative nature. The human resources challenges of the garment industry presented in this study are limited to the Sri Lankan context; samples from other countries might reveal different human resources challenges.

In future research, longitudinal studies might explore how human resources challenges change during the peak business period. Finally, the study was limited to human resources challenges in the garment industry; thus, future research should explore the human resources challenges in other sectors. 


\section{References Références Referencias}

1. Abdur, R. R., \& Atm, A. (2015). Challenges od Ready- Made Garments Sector in Bangladesh, BUFT Journal (3), 77-90.

2. Agbor, E. (2008). Creativity and innovation: the leadership dynamics (Electronic version). Retrieved fromhttp://www.regent.edu/acad/global/publications /jsl.

3. Anand, N., \& Kheterpal, V. (2014). Growth of Apparel Industry in India: Present and Future Aspects. Scholars world, II (I), 64-70. Retrieved from http://www.scholarsworld.net.

4. Braun, V., \& Clarke, V. (2008). Using thematic analysis in psychology. Qualitative research Psychology, 3(2), 77-101.

5. Budget Proposal 2015, Ministry of Finance, Government of Sri Lanka

6. Central Bank Report (2017) Department of Census and Statistics, Sri Lanka.

7. Dheerasinghe, R. (2009). Garment Industry in Sri Lanka Challenges, Prospects and Strategies. Staff Studies, 33(1). http://doi:10.4038/ss.v33i1.1246.

8. Farooqui, M. R. \& Ahmed, M. (2013). Why Workers Switch Industry? The Case of Textile Industry of Pakistan. Asian Journal of Business Management, 5(1) 130-139

9. Gabriel, D. (2015). Cambodia's garment works facing new problems as wages rise. News Report. Retrieved March 2019, fromhttps://p.dw.co m/p/1Ep61.

10. Gavranovic, A. (2018). How to deal with new challenges? Economic, technological and social aspects of the textile and clothing industry, Text Leath Review 1 (1), 29-33.

11. Hancock, P., Carastathis, G., Georgiou, J. \& Oliveira, M. (2015). Female workers in the textile and garment sectors in Sri Lankan Export Processing Zones (EPZs): gender dimensions and working conditions. Sri Lanka Journal of Social Sciences 38 (1): 63-77.http://dx.doi.org/10.4038/sljss.v38i1.7386.

12. Industry Capability Report. (2017). Export Development Board (EDB), Sri Lanka., p. 8.

13. Institute of Policy Studies. (2005). South Asia After the quota, Impact of the MFA system, Sri Lanka.

14. Kelegama, S., \& Epaarachchi (2003). Ready-made garment industry in Sri Lanka: facing the global challenge. Institute of policy studies, Colombo.

15. Kottawatta, K. (2013). Impact of Attitudinal Factors on Job Performance of Executives and NonExecutive Employees in the Apparel Industry in Sri Lanka. Sri Lankan Journal of Human Resource Management, 1 (1). http://doi:10.4038/sljhrm.v1 i1.5111.

16. Liyanage, D. \& Galhena, B. (2014). Determinants of Turnover Intention of Sewing Machine Operators: Case from leading Apparel Company. Kelaniya
Journal of Management, 1(2), pp.107-123. DOI: http://doi.org/10.4038/kjm.v1i2.6535.

17. Lohari, A.G., \& Gopal, K. B. (2013). An overview of HR challenges and opportunities in the textile industry: Current scenario, International Journal of Human Resource Management and Research (IJHRMR), 3 (1), 131-136.

18. Mathis, R. B., \& Jackson, J. H. (2007). Human Resource Management (10th ed.). Singapore: Thomson Asia Pty Ltd.

19. Mc Mullen, A., \& Majumder, M. (2016). Do we buy? A supply chain investigation into living wage commitments from M\&S and H\&M. Labour behind the Lable, Eston Business Centre.

20. Michtell, T. R., \& Lee, T. W. (2001). The unfolding model of voluntary turnover and job embeddedness: Foundations for a comprehensive theory of attachment. Research in Organizational behaviour. 24, 189-246. https://doi.org/10.10 16/S0191-3085(01)23006-8.

21. Natsuda, K., Goto, K., \& Thoburn, J. (2010). Challenges to the Cambodian Garment Industry in the Global Garment Value Chain. The European Journal of Development Research, Palgrave Macmillan; European Association of Development Research and Training Institutes (EADI), 22(4), 469493.

22. Ranaweera, H., (2014). Uplifting Sri Lankan Apparel Industry through Innovation Management to Face the challenges in the post MFA Era. University of Moratuwa, Sri Lanka.

23. Samarasinghe, N., Ariyadurai, S. A., \& Perera, M. E. R. (2015). Facing the Future Challenges of the Sri Lankan Apparel Industry: An Approach based on Porter's Diamond Model for the Competitive Advantage of Nations. Journal of Engineering and Technology of the Open University of Sri Lanka, 3(1), 2279-2627.

24. Shamsuzzoha, A. H. M., \& Shumon, R. H. (2010). Employee turnover: A study of its causes and effects to different industries in Bangladesh. International Journal of Humanities and Social Science (Special Issue), 64-68. https://www.resea rchgate.net/publication/307545809.

25. Sikdar, M. M. H., Shakar, M. S. K., \& Sadeka (2014). Socio-Economic Conditions of the Female Garment Workers in the Capital City of Bangladesh. International Journal of Humanities and Social Science. 4(3), 175-179.

26. Silverman, D. (2013). Doing qualitative research: $A$ practical handbook. Thousand Oaks, CA: Sage.

27. Thammita, U., Seedevi, B., Jayarathne, D., Welianga, A., \& Madushanka, L. (2010). A Study of Employee Absenteeism in the Apparel Industry. Human Resources Management Journal, I (I), 91108. 
28. Thatshayini, P., \& Rajini, P. A. D. (2018). Occupational safety and health hazards of the apparel sector: perspective of Northern Province employees of Sri Lanka. Journal of Business Studies, 5(1), 26-47. http://doi.org/10.4038/jbs.v5i 1.23.

29. The Garment Industry in Sri Lanka. (2018-2019,) Retrieved March 2019, from http://www .ukessays.com/essays/economics/the-garment.

30. Thilakarathne, W. (2006). Phasing Out of MFA and the Emerging Trends in the Readymade Garments Industry in Sri Lanka, 1-30.

31. Ullah, N. M. A. S., \& Rahuman, H. (2013). Compliance management practices on readymade garment industry in Bangladesh: An exclusive study. In $9^{\text {th }}$ Asian Business Research Conference, B.I.A.M Foundation, Dhaka, Bangladesh, 1-9.

32. Yu Ru Hsu (2011). Work-family conflict and job satisfaction in stressful working environments: The moderating roles of perceived supervisor support and internal locus of control. International Journal of Manpower.32,233248.http://doi: 10.1108/014377211 11130224 